\title{
Ato Médico: Perda da Autoridade, Poder e Resistência
}

Medical Act: Loss of authority, power and resistance

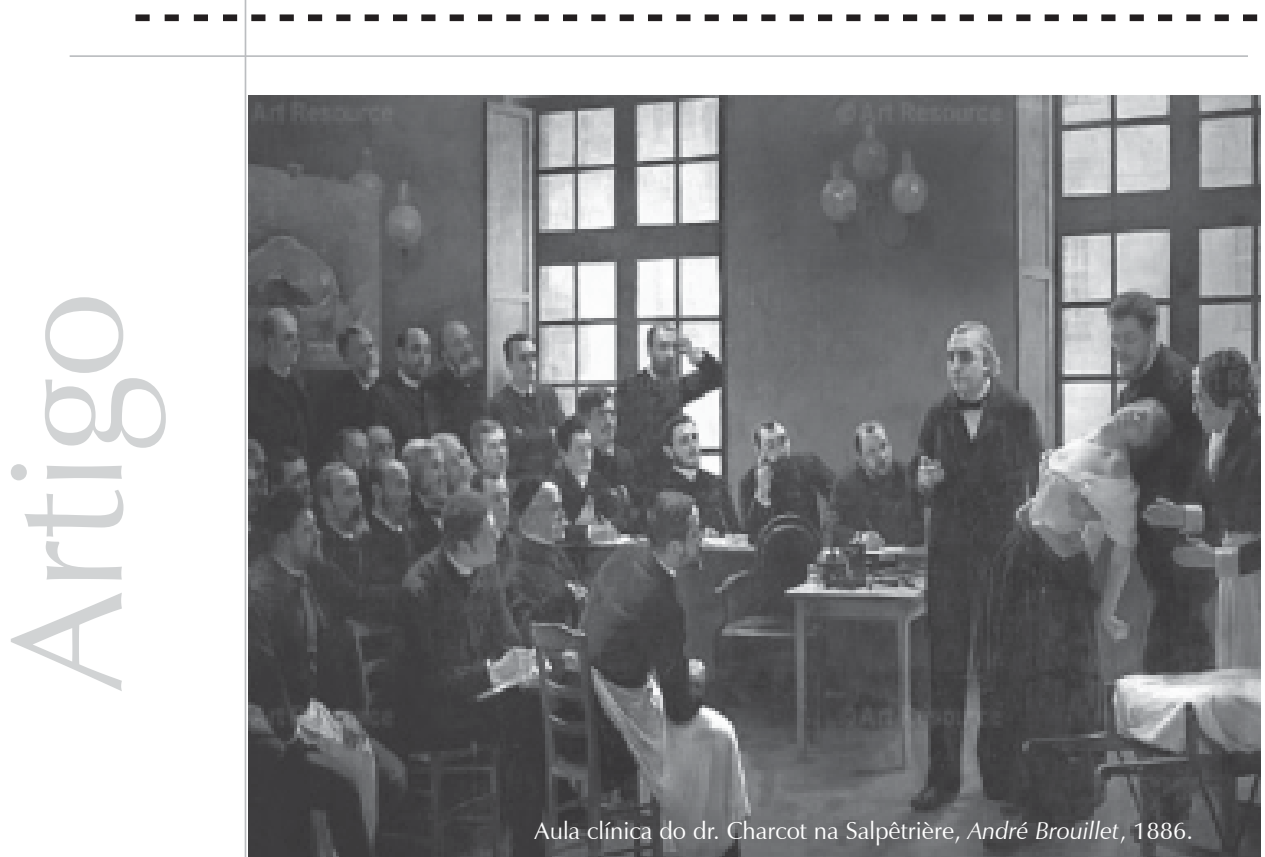




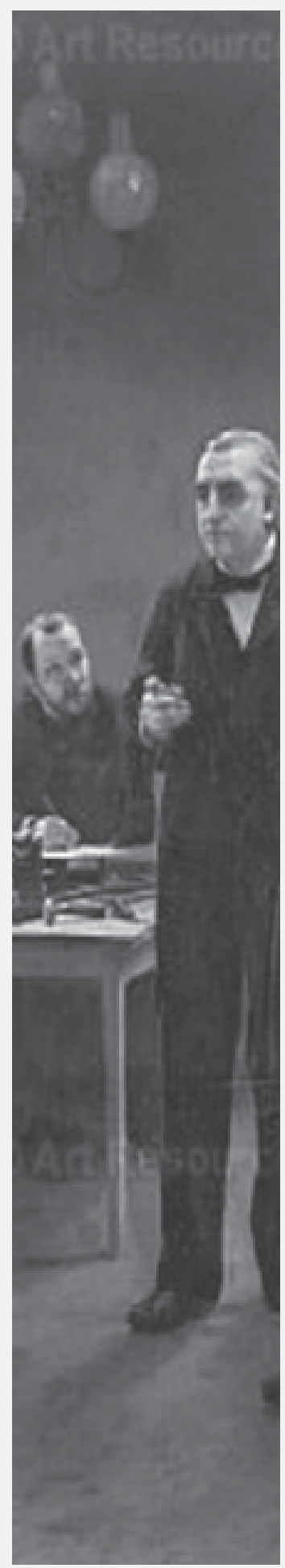

Resumo: Diante do Projeto de Lei no 25/02, que teve a sua gênese a partir da Resolução no 1627/01, do Conselho Federal de Medicina, e o objetivo de condicionar o acesso aos serviços de saúde à autorização do médico, procurou-se conhecer as percepções sobre a atividade médica. Nesse sentido, os autores desenvolveram um estudo qualitativo no campo da saúde do trabalhador, entrevistando 8 médicos do trabalho e 13 trabalhadores. A técnica análise de conteúdo demonstrou que a relação médico-paciente tem-se constituído pelas categorias: submissão, conflito e resistência. Esse tipo de relação reforça a concepção de indivíduo como um mero portador de um corpo biológico e o "ato médico" como uma conjunção de forças culturais, corporativistas e mercadológicas. Assim, esse Projeto de Lei parece constituir uma estratégia para enfrentar a crise atual da hegemonia médica, representando uma regressão aos modelos mecanicista e da mono-causalidade e um desconhecimento das importantes conquistas da Saúde Coletiva.

Palavras-chave: interdisciplinariedade, Medicina, Saúde Coletiva, relação médico-paciente.

Abstract: Facing the Bill no 25/02, from the Brazilian Senate, which had its genesis in the Federal Council of Medicine's Resolution no $1627 / 01$ and the objective of conditioning the access to health services to a previous authorization of the doctor, the authors tried to know the perceptions about the medical activity. In this sense, the same authors have developed a qualitative study in the field of the worker's health, having interviewed 8 doctors and 13 workers. The content analysis technique has demonstrated that the doctor-patient relation has been constituted by the following categories: submission, conflict and resistance. This type of relation reinforces the conception of the individual as a mere bearer of a biological body and the "medical act" as a conjunction of cultural, corporative and marketing forces. Thus, this Bill seems to constitute a strategy to confront the current crisis of the medical hegemony, representing a regression to mechanist and mono-causality models, and demonstrating unfamiliarity with the important conquests on Collective Health.

Key words: interdisciplinarity, Medicine, Collective Health, doctorpatient relation. 
No campo da saúde, repete-se mais do que se percebe ou do que se gostaria, mesmo quando a intenção é acertar e fazer avançar o saber. Há um elevado preço a pagar pela adesão incondicional a determinadas teorias ou modos de pensar, como nos ensina a História. Estudar, criticar e relativizar as conquistas das práticas em saúde, no Brasil, torna-se uma necessidade para que não venhamos a repetir alguns erros, sob pena de reproduzir o dogmatismo. É importante lembrar que toda produção do saber se faz a partir de jogos de verdade (Foucault, 1979), está determinada por quadros prévios de interesses, em Marx (Giannotti, 1978) e Habermas (2000), ou marcada por jogos de linguagem (Wittgenstein, 1979). Assim, é preciso reservar uma especial atenção ao contexto histórico, principalmente aos projetos de lei no campo da saúde, para que possamos analisar, criticamente, as iatrogenias, ideologias e avanços técnicos. Nesse sentido, propomo-nos refletir sobre o Projeto de Lei no 25/02 e seu Substitutivo, em tramitação no Senado Federal (Brasil, 2004), cuja gênese se fez a partir da Resolução no 1627/01, do Conselho Federal de Medicina, de 23 de outubro de 2001 ( CFM, 2001), e que condiciona o acesso aos serviços de saúde à autorização do médico. Uma vez aprovado, o médico assumirá a condição legal de ser o único profissional da saúde autorizado a definir, indicar procedimentos preventivos e terapêuticas nesse campo; além disso, o projeto estabelece, como função privativa do médico, as funções de direção e coordenação das atividades médicas nos serviços de saúde.

O que estaria acontecendo com a Medicina atual que a levaria a buscar, no poder instituído, as bases para o seu exercício? Essas bases têm correspondido às necessidades da população atendida? Ou a Medicina já não estaria em condições de sustentar o seu saber e sua prática diante da demanda de atenção à saúde? É possível que ela esteja encontrando dificuldades. Diante desse fato, essa demanda estaria migrando para outras práticas de saúde organizadas tanto pelo saber acadêmico quanto pelo popular. Em nossa primeira hipótese, para não perder a hegemonia no campo da saúde, a Medicina estaria lançando mão do capital social que ainda dispõe no interior da sociedade na tentativa de impor a sua prática por força de lei, situação referenciada pelos diversos atores sociais. A segunda hipótese é que o Projeto de Lei no 25/02 explicita, de forma clara e distinta, o esgarçamento da figura da autoridade do médico e sua cumplicidade com o poder instituído. Esse Projeto constituiria uma estratégia forjada pela Medicina para enfrentar a crise atual de sua hegemonia diante de um mercado pósindustrial, de uma transdisciplinaridade emergente e de um resgate crescente das práticas populares de cuidados médicos.

Em termos teóricos, para compreender a existência desse projeto, que envolve perda da autoridade, inicialmente, traçamos uma breve trajetória histórica, que vai do surgimento da Medicina científica, no século XIX, à Saúde Coletiva, nas últimas décadas do século XX. Em seguida, analisamos as diferenças entre os termos autoridade e poder, facilmente confundidos na literatura. Para isso, recorremos a Hannah Arendt, em "O que É Autoridade", de 2001, onde foi possível constatar uma ênfase no papel da tradição como fundamento para a autoridade. Por fim, contemplamos a fala e a memória de alguns pacientes e médicos para assinalar que a perda da autoridade médica se faz presente, também, na relação médicopaciente.

Neste estudo, buscou-se assinalar: 1) que o Projeto de Lei no 25/02 e seu Substitutivo está relacionado com a perda da autoridade e a centralização do poder médico; 2) que na trajetória que vai do "nascimento da clínica" à instituição da saúde coletiva, o Projeto representa uma regressão ao retomar os modelos mecanicista e da mono causalidade no campo da saúde; 3) algumas situações de perda da autoridade, poder e resistência que ocorrem na relação médico-paciente, no contexto do mundo do trabalho, pilar fundamental para uma sociedade movida pelo capital. 


\section{Silenciando pacientes e profissionais da saúde}

O "ato médico" pode ser compreendido também através da passagem da relação médico-paciente fundamentada na escuta do sujeito para uma outra centrada no "ver e dizer", iniciada com a Medicina científica, no século XIX. Se, naquele século, a Medicina procurou silenciar o paciente, na atualidade, com o Projeto de Lei no 25/02 e seu Substitutivo, ela tenta "diminuir a voz" de profissionais da Biologia, Enfermagem, Farmácia, Fonoaudiologia, Nutrição, Odontologia, Psicologia e Serviço Social.

Fazendo uma breve retrospectiva histórica, anterior e diferentemente da Medicina classificatória, a Medicina das espécies empenhava-se em uma atenção ao sujeito, buscando auscultar sua história e sua percepção acerca do que Ihe ocorria. Era comprometida com a construção de um vínculo, que incluía também a família, médico e paciente, implicados em uma proximidade crescente à medida que os cuidados eram dispensados, pois, em geral, a casa do paciente era o lugar onde essa relação acontecia. No início do século XIX, a partir de uma ruptura que se estabeleceu no saber médico, uma nova forma de cuidados médicos modificou essa relação. Com o advento da Medicina classificatória, novas formas de conhecimento e novas práticas institucionais destituíram o paciente da sua condição de sujeito. Para conhecer a "verdade do fato patológico", o médico abstraía o sujeito, pois sua disposição, temperamento, fala e modos de vida poderiam perturbar a identificação da doença segundo o desenho nosográfico daquela época. O papel dessa lógica era neutralizar essas perturbações, manter a subjetividade distante para que a configuração ideal da doença aparecesse aos olhos do médico, no vazio que se instaurava entre pacientes e médicos. Na atualidade, a Medicina classificatória ainda concebe a doença como natureza que aparece através de um corpo real, aos olhos de um médico munido de um arsenal para ver, identificar e dizer aquilo que viu segundo um vocabulário próprio. Para o médico, a fala do doente oculta e confunde o que há de visível na doença. Segundo essa racionalidade, o olhar clínico deve dirigir-se, então, para o espaço do corpo, que é o espaço da patologia. Silencia-se, assim, o paciente, que, muitas vezes, em vão, tenta falar de seu sofrimento e daquilo que imagina ser o seu mal (Foucault 1979; 1998).

Assim, a doença é destacada de sua metafísica da maldade, da qual tinha sido parte durante séculos, e passa a ocupar um estado corporal que permite a leitura da ciência. É nesse contexto que a Medicina clínica proporciona significativas contribuições para o fim da concepção religiosa e individual da doença, silenciando as reações do sujeito e sua manifestação de sofrimento frente às adversidades ou fragilidade da vida. O sintoma assume o significado de determinante natural das doenças, deixando de lado a expressão de uma indissolubilidade e de uma específica ligação entre sujeito, sofrimento e adoecimento. No momento em que o discurso clínico assumiu a sua forma como tal, o sujeito desapareceu da cosmologia médica, dificultando a visibilidade da milenar articulação do saber com o sofrimento, fazendo surgir o paciente e seu conjunto de órgãos. Na consulta, "colhem-se apenas dados" que podem conduzir ao diagnóstico de uma doença que se torna mais importante que o próprio sujeito. O médico preocupase com o diagnóstico e esquece-se de seu "porta-dor", pois o profissional precisa ser científico. O sintoma deixa de ser representado como sinal ou tentativa de solução de conflito para tornar-se sinônimo de doença. Dessa maneira, tudo parece indicar uma confusão entre sinal e sintoma, sintoma e signo, signo e significado, significado e significante (Brant, 2001).
O "ato médico" pode ser compreendido também através da passagem da relação médicopaciente fundamentada na escuta do sujeito para uma outra centrada no "ver e dizer", iniciada com a Medicina científica, no século XIX. 


\section{O hospital e a desqualificação das práticas curativas familiares}

O hospital, como um dos lugares da construção da identidade de doente e intervenção médica, constituiu um importante instrumento na formação da hegemonia dos cuidados médicos em relação às outras práticas de saúde existentes no âmbito da comunidade. Representou, ainda, um importante elemento na consolidação do poder médico e de sua visibilidade social. Uma vez hospitalizado, não havia dúvidas de que se estava doente e do poder do médico para determinar o momento da internação e da alta. Mas, para isso, seria necessário destituir as práticas médicas familiares. A partir do domínio hospitalar, a residência deixou de ser o lugar onde o sofrimento se manifestava em sua forma possível e a família perdeu a autoridade sobre as maneiras de cuidar do seu ente, que seria, doravante, isolado e "olhado cientificamente" (Foucault, 1979). No hospital, com os especialistas ilusoriamente próximos, acreditava-se na possibilidade de reparar os excessos ou deficiências das práticas familiares em relação ao processo saúde-doença-cuidado. Introjetada uma ordem médica, que desqualifica as suas práticas curativas, a família se viu obrigada a solicitar atenção de médicos por se perceber impotente diante das manifestações de sofrimento, representadas como sinais de doença. Grande número de hospitalizações desnecessárias, pessoas identificadas e estigmatizadas como doentes, são, muitas vezes, conseqüências históricas desse processo.

De forma semelhante, os cuidados com loucos, organizados pela comunidade, também foram transferidos para o poder médico com a criação dos hospitais psiquiátricos. No Rio de Janeiro, até a segunda metade do século XIX, os loucos que perambulavam pelas ruas da cidade, quando perturbavam a ordem pública, eram colocados nas prisões ou internados na Santa Casa de Misericórdia, ou seja, não recebiam nenhuma assistência médica específica. Quanto a esse aspecto, nada os diferenciava dos mendigos e outros marginalizados. A partir de 1830, um grupo de médicos higienistas advoga a urgência de um asilo onde os loucos pudessem ser tratados segundo os princípios do tratamento moral, ou seja, começa-se uma exigência: diagnosticados como doentes mentais, deveriam ser tratados medicamente em local exclusivo, sendo essa prática considerada um "avanço científico" da Medicina. Também representado como uma "conquista da ciência", como nos lembra Michel Foucault (1978), os loucos arrebanhados pelas autoridades dos primeiros anos da Idade Moderna eram empilhados nas Narrenschiffen (naus dos loucos) e jogados ao mar, realizando-se, portanto, a higiene da cidade.

Segundo Costa (1989), em 1923, criou-se a Liga Brasileira de Higiene Mental - LBHM e, em 1934, o governo promulga a Lei Federal de Assistência aos Doentes Mentais, que "Dispõe sobre prophylaxia mental, assistência e proteção à pessoa dos psicopatas e a fiscalização dos serviços psychiatricos". Mesmo que, na atualidade, nos encontremos, temporalmente, distantes do ideal eugênico das primeiras décadas do século XX, a criação da LBHM permanece paradigmática à medida que sinaliza a necessidade de conceder especial atenção ao papel dos contextos históricos na elaboração de projetos de lei que versam sobre prevenção, de modo que não venhamos a reproduzir os erros e equívocos cometidos em nome da ciência, que a História se encarregou de revelar. É importante ressaltar que o parágrafo único do art. $1^{\circ}$ do Projeto de Lei no 25/02 estabelece: "As atividades de prevenção de que trata este artigo, que envolvam procedimentos diagnósticos de enfermidades ou impliquem indicação terapêutica, são atos privativos do profissional médico". Não se pode esquecer que é em nome da prevenção que, na Alemanha de Hitler, cerca de 45\% dos médicos apoiaram o projeto nazista. Toda "intervenção preventiva" produz desordens, em maior ou menor grau, 
pois o médico, portador de um interesse disseminado em jogos de palavras, é sempre um estranho diante daquele que não formulou sua demanda, mas que é visto, a priori, como paciente em potencial.

Se, na época de sua fundação, a LBHM tinha como objetivo melhorar a assistência aos doentes mentais através da renovação dos quadros profissionais e dos estabelecimentos psiquiátricos, cinco anos após, a reformulação de seus primeiros estatutos dá lugar importante à intervenção preventiva dos psiquiatras no âmbito escolar, profissional e social. Os psiquiatras, definindo-se como higienistas, gradativamente, deslocaram-se da prática tradicional e penetraram no domínio cultural, até então fora dos domínios da Psiquiatria, com uma proposta de trabalho apoiada na noção de eugenia, noção essa que justificava "cientificamente" a invasão do campo social pela higiene mental. No entanto, foi com as campanhas antialcoólicas que a LBHM parece ter recebido apoio do Governo da Revolução de 30 e, assim, ter implementado uma severa vigilância policial aos alcoólatras, delinqüentes e outros marginalizados. Com a criação do Departamento Nacional de Saúde, foi possível reagrupar as instituições psiquiátricas do País, que haviam, aparentemente, aderido aos ideais de combate ao alcoolismo propostos pela LBHM com medidas cada vez mais autoritárias. Embora o alcoolismo estivesse distante de ser a epidemia em que os psiquiatras desejavam transformá-lo, estava, no entanto, próximo da crença médica de intervir, eugenicamente, na sociedade. Acreditando que as campanhas antialcoólicas tivessem atingido o "ponto de saturação" e dispondo de um sistema médicopolicial organizado no plano nacional, os psiquiatras da LBHM idealizaram ampliar a intervenção da higiene mental em outros relevantes espaços sociais e a toda a população, o que significa uma tentativa de passagem da higiene mental à higiene social, conduzida por uma intensificação da propaganda eugênica no Brasil: o que é sujo e impuro deve ser mantido distante ou enclausurado para o bem-estar da coletividade limpa e pura, de modo que a ordem e o progresso possam estar assegurados (Costa, 1989).

A passagem de uma proposta de trabalho com indivíduos diagnosticados como doentes para uma prática com não doentes implica deslocamento do domínio circunscrito a uma prática médica instituída para o campo social como um todo. Denominado como prevenção, esse deslocamento tenta subordinar cidadãos sem demandas de cuidado aos critérios de cientificidade da prática médica, incutindo um ideal muitas vezes forjado alhures à realidade do convocado para receber o que se julga melhor para ele. Se, no campo da "saúde mental", o exercício da prevenção pode ser considerado historicamente falido, no entanto, dois pilares - a noção de sujeito universal e a noção de predição controladora das condutas que a sustenta - permanecem firmes e continuam fundamentando e parasitando teorias e ações nas áreas da saúde e do trabalho. Prevenção implica "pré-dizer", imaginariamente, a existência de uma doença no horizonte e os mecanismos para evitá-la; assim procedendo, a Medicina fornece elementos lingüísticos para uma comunidade nomear com vocabulário médico situações pertencentes ao seu universo cultural.

Nas últimas décadas do século XX, no âmbito da Medicina, já era possível observar uma quase completa desqualificação das práticas de cuidados organizadas pelas famílias e pela comunidade. Lidar com o processo saúdedoença-cuidado tornou-se função quase exclusiva dos médicos. Como resultado, a norma curativa familiar, agora produzida pela ordem médica, passou a solicitar, diante de qualquer manifestação do sofrimento, intervenções dos médicos, verdadeiros agentes disciplinares (Costa, 1989). Seguindo essa lógica, estando a família submetida à ordem médica, tornou-se, então, necessário submeter outros profissionais da saúde a essa mesma ordem, de 
modo que a hegemonia dos cuidados médicos pudesse prevalecer. Eis a função última do Projeto no 25/02, segundo nossa ótica.

\section{O "ato médico" e a tentativa de desqualificação do campo da Saúde Coletiva}

A partir dos anos 70, do século passado, operouse, no Brasil, um movimento de profissionais da saúde, de pesquisadores e da sociedade civil para a integração das ações de saúde como forma de responder efetivamente às demandas apresentadas pela população. A estruturação das práticas sanitárias da saúde pública não conseguia cobrir a amplitude e a complexidade exigidas pelo contexto social. Esse movimento, denominado Saúde Coletiva, estruturou-se através de questionamentos quanto às bases teóricas e práticas da saúde pública e tinha como objetivo estabelecer concepções sobre as condições de vida e saúde. Com ele, procurou-se descobrir um meio de intervir e fazer com que os órgãos governamentais assumissem a dimensão política do campo da saúde baseados em princípios como o da cidadania (Donnangelo \& Pereira,1979; Nunes,1983; Melo, 2002).

Ao articular a saúde com os campos das ciências sociais e das ciências políticas, a Saúde Coletiva possibilitou um melhor entendimento do processo saúde-doença e a formulação de estratégias mais efetivas para a intervenção junto à demanda da população por melhores condições de vida. Com isso, tornou-se possível redefinir os conceitos de saúde/doença e de Estado ampliado, buscar mudanças qualitativas e conquistas sociais de base para a maioria da população e revisar o sistema de saúde, considerado defasado em relação às necessidades e aspirações da população (Nunes, 1985; Minayo, 1991). Assim, iniciava-se um movimento para ultrapassar os limites da clínica, cujo propósito era um fazer em saúde a partir do 'mundo da vida', um fazer que transcende o objeto, a razão 'pura', buscando entender a complexidade das relações sociais para além das "ações clássicas" do campo da saúde, ações essas verticalizadas em torno das práticas educativas que, normalmente, negligenciam o saber constitutivo dos sujeitos sociais com os quais se trabalha. Iniciava-se uma oposição crítica ao naturalismo do saber médico hegemônico (Paim, 1995; Canesqui, 1995).

A articulação do campo da saúde com o das ciências sociais possibilitou a explicação da multicausalidade do processo saúde-doença, associando os fatores biológicos a fatores socioculturais. Desenvolveu-se uma prática científica rigorosa e competente, crítica e sensível às desigualdades dos povos latino-americanos. A Saúde Coletiva, como campo de conhecimento, conseguiu demonstrar a amplitude das suas possibilidades e a especificidade do seu objeto. Seu grande desafio era transcender os limites das disciplinas clínicas que, centralizadas apenas nos aspectos biológicos, não tinham conseguido reconhecer a real necessidade de trabalhar com o mundo da vida (Canesqui, 1997). Em síntese, pode-se dizer que Saúde Coletiva é a perspectiva de um novo paradigma para a saúde, entendendo o processo saúde-doença como um processo histórico e social, propondo mudanças sustentadas na filosofia da promoção da saúde. Trata-se de um campo em permanente construção, que se baseia em princípios de interdisciplinaridade e intersetorialidade, preocupando-se com a saúde pública enquanto do público ( Paim \& Almeida Filho, 1998).

Ainda na década de 70 do século XX, a hegemonia das práticas curativas médicas é ameaçada por um movimento denominado Promoção da Saúde, que nega a utilidade social desempenhada por investimentos centralizados no setor de prestação de serviços médicos curativos e preventivos. Trata-se, portanto, de uma reação ao aumento acentuado dos custos da atenção médica, o que leva à procura de caminhos alternativos que possam conter essa tendência inflacionária. Questiona-se, assim, a 
acentuada medicalização como as únicas estratégias para produzir mudança das condições de saúde (Lalonde, 1974; Buss, 1998). Na tentativa de ultrapassar as fragmentadas e isoladas políticas do setor saúde, de afastar-se do modelo clássico da história natural da doença e de redesenhar linhas metodológicas de pesquisas na saúde, esse movimento tem como base uma concepção ampla do processo saúde-doença-cuidado e de seus determinantes. Pode-se dizer que a Promoção da Saúde implica uma combinação de estratégias: ações do Estado (políticas públicas saudáveis), da comunidade (reforço da ação comunitária), de indivíduos (desenvolvimento de habilidades pessoais), do sistema de saúde (reorientação do sistema de saúde) e de parcerias intersetoriais. Nessa perspectiva, a Promoção da Saúde trabalha com a idéia de responsabilização múltipla, seja pelos problemas seja pelas soluções propostas para os mesmos.

Enquanto produção de saber, a Saúde Coletiva e, mais recentemente, o paradigma da Promoção da Saúde constituíram e constituem um conjunto de práticas sociais pertencentes ao campo da saúde (Brant \& Melo, 2001). Como campo de conhecimento e de intervenção, elas se afirmaram como processos críticos a partir de um movimento dinâmico e uma função otimizadora; tendiam, portanto, ao aperfeiçoamento da atenção à saúde. No Brasil, em pleno processo de reforma sanitária, sob o primado das teorias da determinação social, grandes foram as contribuições da Medicina Social Latino-Americana para o entendimento da complexidade das questões relativas ao processo saúde-doença-cuidado. Nesse contexto, estabelecendo uma ruptura com o utópico conceito da Organização Mundial de Saúde, de 1946 (WHO, 1946), a saúde é, então, redefinida, na VIII Conferência Nacional de Saúde (Brasil, 1986), como "resultante das condições de alimentação, habitação, educação, renda, meio ambiente, trabalho, transporte, emprego, lazer, liberdade, acesso e posse da terra e acesso a serviços de saúde. É assim, antes de tudo, o resultado das formas de organização social da produção, as quais podem gerar grandes desigualdades".

Ao chegarmos ao final deste breve percurso, não temos dúvidas em afirmar que a Saúde Coletiva, no Brasil, estabeleceu uma ruptura com as concepções hegemônicas da Medicina que estabelecem articulações simplificadas entre causa e efeito, desconsiderando a dimensão social e histórica do processo saúde-doença. A partir dessa trajetória histórica, do ponto de vista epistemológico, o "ato médico" pode ser interpretado como um vetor de força que busca explicação unicausal para a complexidade do processo saúde-doença-cuidado. Portanto, visa a impedir o novo, o questionamento, as atividades criadoras, em síntese, os avanços do campo da Saúde Coletiva, conforme já demonstrado. O Projeto no 25/02 e seu Substitutivo visam a manterP práticas médicas estabelecidas, cristalizadas, e direitos corporativos através do poder instituído. Esse projeto nos leva a deduzir que os avanços da interdisciplinaridade no campo da saúde estaria remetendo a Medicina uma "crise da autoridade", uma vez que o modelo biomédico já não consegue responder às demandas de atenção à saúde da sociedade atual. Concluímos que, nesses dois séculos de "Medicina científica", embora houvesse desejo de mudança, renovação das práticas e investimentos das mais diversas ordens, atos iatrogênicos e violências foram e são cometidos, ainda, em nome da ciência, da saúde e do bem-estar da população.

\section{Perda da autoridade e poder}

O ato médico utiliza meios externos à Medicina, instaurando um processo de argumentação no Senado na tentativa de instituir, por força de lei, o seu fazer em saúde. "Onde a força é usada, a autoridade em si mesmo fracassou", afirma, categoricamente, Arendt (2001, p.129). Em uma dada situação, a argumentação, uma vez utilizada como recurso de convencimento ou de persuasão, abole a autoridade como tal. O
Ao chegarmos ao final deste breve percurso, não temos dúvidas em afirmar que a Saúde Coletiva, no Brasil, estabeleceu uma ruptura com as concepções hegemônicas da Medicina que estabelecem articulações simplificadas entre causa e efeito, desconsiderando a dimensão social e histórica do processo saúdedoença. 
Projeto de Lei no 25/02 e seu Substitutivo são a clara evidência de que a autoridade médica, construída ao longo dos séculos, se encontra esgarçada. Na tentativa de manter-se como uma referência de atenção à saúde, a autoridade médica é transformada em autoritarismo. Para que se possa compreender essa perda da autoridade, torna-se necessário, primeiramente, definir esse termo para distingui-lo de poder, que, como ele, também é capaz de provocar obediência.

Na filosofia política grega, principalmente em Aristóteles e Platão, a autoridade sustenta-se na noção de perícia, cujo conteúdo é extraído tanto da família quanto do mundo da "fabricação" e das artes. Nesse universo, pastor, médico, timoneiro e professor constituem exemplos de autoridade. Para Platão, o despotismo tem origem na família e pode destruir a esfera política. De acordo com o pensamento platônico, a autoridade implica obediência, na qual os homens retêm sua liberdade; assim, esse filósofo outorgou às leis a qualidade que tornaria os governantes inquestionáveis em todo o domínio político. Em nenhum outro lugar o conceito de autoridade é claramente demarcado como na República, onde Platão colocou, frente a frente, a realidade da polis e o utópico governo da razão na pessoa do rei-filósofo.

Já na tradição romana, autoridade está ligada às noções de tradição e religião; tem suas raízes na palavra auctoritas que, etmologicamente, vem de augere, aumentar e desenvolver-se, ou seja, autoridade depende da vitalidade do espírito, da fundação em poder preservar e manter seus valores. Religião e atividade política se identificavam, sendo que a primeira significava, entre os romanos, literalmente, religare, ou seja, ser ligado ao passado. A continuidade desse "aumentar" apenas podia ocorrer através da tradição, ou seja, através da transmissão, na continuidade dos sucessores, da norma inaugural estabelecida no princípio. Ela inaugura e preserva, ao mesmo tempo, e seu princípio originário é a experiência da fundação de Roma, o começo, que, por sua vez, deverá permanecer obrigatório para todas as gerações futuras. Enquanto o poder (potestas) era temporal, a autoridade encarnada no Senado romano tinha raízes no passado, que se fazia presente na vida real da cidade e não possuía poder, no sentido de governar. Participar da política tinha, como sentido, preservar a fundação da cidade de Roma. A autoridade, na concepção dos romanos, meramente aprova ou desaprova, "aumenta" ou confirma a ação dos homens, mas não os governa, pois só o poder de quem governa pode guiar. Para melhor compreender o sentido da palavra autoridade, vale lembrar que auctor quer dizer "autor", aquele que inspirou (diferenciado daquele que executou), e cujo espírito permanece representado na obra, sendo, portanto muito mais efetivo que o construtor, que tão-somente faz. A relação entre o auctor e o artifex não é dada entre o senhor que manda e o escravo que obedece, pois a característica maior da autoridade, entre os romanos, é ser destituída de poder.

De forma semelhante ao pai na família e ao líder espiritual na religião, os médicos também perderam sua grandeza e autoridade de outrora, já não constituem modelo de identificação ou referência. No mundo pós-industrial e sob o império do liberalismo, não há tempo e espaço para a tradição e permanência, condições necessárias à autoridade. Sob o imperativo do "tudo-já, a qualquer custo", tudo a qualquer momento, pode transformar-se em outra coisa. Nesse contexto, em sua maioria, os médicos tornaram-se funcionários, seja ocupando cargos em instituições seja em seus próprios consultórios quando estão submetidos aos planos e seguros de saúde. Assim, eles exercem poder em decorrência da ocupação legítima de um cargo, mas não necessariamente têm autoridade.

Nessas circunstâncias, o exercício da Medicina está condenado a enfrentar grandes dificuldades 
tanto para aqueles que cumprem papéis quanto para os que trabalham a partir de "um solo firme". Desempenhar papéis significa não ser auctor. Sendo aquele que representa, o seu espírito não permanece na obra, apenas segue o script. Tal qual o papel, é passível de manipulação, de substituição, e aceita tudo, como se diz popularmente. Enquanto artifex, os profissionais que detêm vínculo empregatício devem realizar um determinado número de procedimentos cujo não-cumprimento é passível de sansão. Mesmo para aqueles que trabalham em consultórios particulares, muitas vezes, essa relação é reproduzida. Sob a tutela dos convênios, muitos tentam melhorar o faturamento atendendo um grande número de pacientes, reduzindo o tempo de duração das consultas, principalmente quando o paciente é originário de frações das classes populares. "A duração da consulta médica parece diminuir bastante com a classe social do doente" (Boltanski, 1979, p.59). De forma inteiramente distinta, exercer a Medicina a partir de uma posição implica um ethos, que deverá dar sustentação aos atos. Essa posição, enquanto solo firme, é o princípio, a origem, a fundação que se manifesta no cuidado ao escutar e no falar com o paciente. Enquanto autoridade, a função do médico consiste em oferecer atenção acerca do processo saúde-doença-cuidado e, assim, acrescentar e desenvolver os fundamentos e as práticas que haviam sido estabelecidos pelos antepassados (médicos ou não), no interior da comunidade. É somente desse lugar que é possível diferenciar "ato do médico" de "ato médico". O primeiro se refere às ações próprias do médico de acordo com seus interesses particulares, enquanto o segundo é definido pelo ethos, ou seja, ato essencial, inexoravelmente marcado pela solidariedade que envolve o médico e paciente (Corrêa, 2003).

\section{Material e Método}

Este trabalho está situado no domínio das pesquisas qualitativas, nas quais o sentido não é construído a partir de uma situação isolada, mas, sim, de um conjunto de situações. Nesse sentido, investe-se na possibilidade de explorar um tema sem pretender verificar hipóteses levantadas a priori (Triviños, 1987).

A amostra se constituiu de 21 pessoas, sendo 13 trabalhadores de uma empresa prestadora de serviços na cidade de Belo Horizonte e 08 médicos do trabalho, sendo 04 funcionários da empresa e 04 sócios de uma consultoria que presta serviços a essa empresa na área de saúde e trabalho. Todos foram submetidos a entrevistas semi-estruturadas, individuais e gravadas. $\mathrm{O}$ método escolhido para a análise dos dados foi o de análise de conteúdo (Bardin, 1977; Triviños, 1987; Minayo, 1996).

\section{Resultados e discussão}

Através da técnica de análise de conteúdo, ficou evidente, nas entrevistas, que a relação médicopaciente parece constituir-se das seguintes categorias de análise: submissão, conflito, resistência e a "escuta" diferenciada.

Conflito

"Você vê gente se queixando de dor no ombro esquerdo que não trabalha com o ombro esquerdo, trabalha com a mão. O trabalho dele não tem nada a ver para ele desenvolver uma dor no ombro. Hoje, há um aproveitamento muito grande" (RS, médico, 31 anos).

Esse entrevistado parece reforçar a obediência de alguns profissionais da área médica a uma lógica estabelecida pelos manuais acadêmicos ou à sua própria experiência, deixando de escutar, desqualificando ou duvidando das queixas do paciente, posicionamento característico de uma relação médico-paciente permeada por conflitos, onde se observa a busca de cuidados e, na oferta do trabalho, tentativas de dominação e resistência. De acordo com Boltanski (1979), a história da Medicina, pelo menos há um século, é a história de uma luta contra as práticas médicas populares com o objetivo de impor a autoridade do médico.
"Você vê gente se queixando de dor no ombro esquerdo que não trabalha com o ombro esquerdo trabalha com a mão. O trabalho dele não tem nada a ver para ele desenvolver uma dor no ombro. Hoje, há um aproveitamento muito grande" (RS, médico, 31 anos). 
"Ele me olhava com uma cara como se eu estivesse mentindo, como se eu estivesse brincando de ficar doente (risos), me dá tanta raiva, que dá vontade de chorar. Vê lá, se a gente brinca de ficar doente...." (TG, operária, 29 anos).

Esse relato demonstra, com clareza, a percepção dos pacientes quanto à distância entre aquilo que relatam e a observação do profissional. Não se pode esquecer que a relação doente-médico é, primeiramente, "uma relação de classe e que o médico adota um comportamento diferente conforme a classe social do paciente" (Boltanski, 1979, p.39).

"Eu sentia dores no ombro, cotovelo, dedos. Me encaminharam para um ortopedista que pediu um raio x, não constatou nada. Continuei trabalhando com dor, o médico só pensou no prejuízo da empresa, esqueceu a minha dor. Os colegas indicaram outro ortopedista. Lá, havia uns 8 colegas fazendo tratamento, todos com dor no braço. Ele pediu ultra-sonografia, a consulta durou uns 40 ou 50 minutos. Deu epicondilite lateral..." (BV, operário, 48 anos).

"Os funcionários já sabem, Dr. Fulano, Dr. Beltrano e Dr. Sicrano dão atestado de dor, dão relatório, mandam emitir CAT e afastam. Então, eu tenho que barrar isto" (ER, médico, 59 anos).

Os entrevistados acima explicitam a diferenciação dos atendimentos, que pode estar sustentada na distância social que separa pacientes e médicos e que foi percebida por aqueles que trabalham no chão-de-fábrica. Eles sabem que, embora possuindo o mesmo vínculo empregatício que os médicos, (no caso da Medicina Ocupacional), pertencem a estratos sociais distintos, e os médicos adotam atitudes diferentes conforme a aparência do paciente. Fazendo parte "dos outros", como mostrou Willis (1991), o médico, enquanto representante de um universo estranho e guardião de determinados interesses sociais, foi percebido pelos pacientes com desconfiança e cautela. No chão-de-fábrica, os operários eram divididos entre "os nossos" e os "peixinhos do chefe". Os "nossos" eram aqueles com os quais se pode compartilhar as transgressões, o gosto pelo trago, os pequenos furtos e as questões sexuais. Com esses, aprende-se também quais profissionais deverão procurar para serem atendidos conforme a expectativa, onde encontrá-los, o que relatar e o que não pode ser comentado. No entanto, essa estratégia coletiva de sobrevivência, no interior da fábrica, era conhecida pelos médicos.

No contexto da "crise da autoridade" em que se encontrava a Medicina, alguns médicos se viam obrigados, diante do paciente, de outros profissionais da saúde e das práticas médicas populares, a estabelecer estratégias de persuasão para fazer-lhes reconhecer seu diagnóstico e conduta clínica. Em relação aos profissionais não-médicos, tentavam demonstrar que o diagnóstico, resultado de entrevista clínica e bateria de exames complementares, estava correto. Quanto maior a tentativa de convencimento, maior era a falta de autoridade. Para fazer-se reconhecido em sua autoridade médica, a estratégia inicial de alguns consistia na desqualificação do sofrimento, percepções e sensações do paciente. Muitas vezes, representado como "desprovido de inteligência" e incapaz de empregar termos corretos para se expressar, o paciente originário das camadas populares era submetido a um rigoroso exame físico e exames complementares. Deixar pouco espaço para a fala do paciente constituía também uma estratégia, pois ela mais atrapalhava do que colaborava com o diagnóstico, preconizado, segundo Clavreul (1983), sob bases científicas, razão única e suficiente para a sua consolidação. Quando o paciente era classificado na categoria "transtornos mentais", como no caso relatado acima, uma outra estratégia utilizada para a confirmação da autoridade médica era encaminhá-lo ao psiquiatra. O doente era, ainda, orientado para solicitar deste um laudo que deveria ser apresentado no momento da perícia do INSS. O objetivo consistia em 
subsidiar e convencer o colega acerca do diagnóstico, de modo que não ficasse nenhuma margem de dúvida. Mas nem sempre prevalecia o consenso diagnóstico.

\section{Submissão}

"Fiquei esperando 3 horas e meia, a consulta durou 15 minutos. O médico leu, superficialmente, os laudos, só virava as páginas. Perguntei se ele não ia me examinar, disse que não era necessário. Os laudos eram suficientes. Então, pensei: não precisava ter ido. É um desdém tão grande, parece que não estão lidando com pessoas" (TG, operária, 29 anos).

Se os pacientes se sentiam tão pouco inclinados a confiar na autoridade médica era, em primeiro lugar, porque verificavam que alguns profissionais não os acolhiam devidamente nem forneciam um mínimo de informações compreensíveis sobre o seu processo saúdedoença. A exclusão se faz necessária, pois não há espaço para o discurso médico e para o discurso do paciente; assim, a "escuta" seletiva do profissional tem priorizado apenas o que entende ser importante para a sustentação do discurso médico.

Saber que seria submetido a uma avaliação médica, denominada perícia, era, por si só, fonte de angústia. Sensíveis ao comportamento do médico, os pacientes, quando submetidos à perícia do INSS, reparavam todas as atitudes em relação a eles, olhavam meticulosamente o ambiente e o tempo de duração da consulta. Ao saírem, geralmente, sentiam-se desqualificados e desrespeitados como pacientes e cidadãos.

"Três médicos acham que devo permanecer afastado, o médico do INSS acha que eu já poderia ter voltado ao trabalho. Minha vontade de voltar não está contando muito, acho que a culpa é minha, não soube me expressar direito" (CS, operário, 52 anos).
Outros constatavam a inexistência de uma prática médica coerente à medida que obtinham diferentes diagnósticos de diferentes profissionais. Verificavam, também, que a percepção que tinham acerca do seu estado de saúde não era levada em consideração. Observou-se, além disso, a existência de uma auto-culpabilização por não se saber falar sobre o próprio estado de saúde. A raridade dos contatos com o médico e a pequena duração de cada entrevista tornavam difícil, para os pacientes originários das camadas populares, personalizar a fala que mantinham com o médico (Boltanski, 1979). A presença dessa auto-culpabilização poderia, também, estar sinalizando a perda da autoridade médica. Segundo a Psicanálise, a percepção de uma falta naquele que poderia encarnar a figura do Grande Outro é por demais angustiante para o sujeito. Para Lacan (1998), o sujeito tenderia a colocar a falta em si mesmo como uma forma de preservar o Outro em sua completude. "Por minha culpa, por minha máxima culpa", tal como o pecador da oração cristã, o paciente, muitas vezes, assumia toda a culpa daquilo que sucedia na sua relação com o médico, pois, se não for sua, então seria culpa do médico? A culpa possui valor epistêmico; "por minha culpa" implica uma pergunta sobre a causa, um questionamento do paciente sobre a origem do descaso que sofre na consulta. O sentimento de culpabilidade seria uma maneira de dar sentido a essa falta de atenção do médico. É preferível assumir a culpa do que se deparar com o vazio que a perda da autoridade médica abriria na relação com o paciente. Enquanto a falta estiver no sujeito, é possível repará-la através de penitências, reciclagens, etc.; estando no Outro, nada resta senão a angústia, donde se conclui que a perda da autoridade na figura que o médico encarnava não podia ser algo tranqüilo para o paciente.

"Tem uma funcionária afastada por LER, ela inventou mil coisas, porque ela não consegue assimilar a cobrança de trabalhar aqui" (ER, médico, 59 anos). 
Mas, ao colocar-se como culpado, o paciente estava também reproduzindo um discurso médico comum no interior das instituições. Assim, o processo de adoecimento era entendido como um fator diretamente ligado à esfera individual. A responsabilização do sujeito pela sua doença denotava um "esquecimento" de que a saúde não é fruto de um estilo de vida, pois não é plasmada por opções pessoais e, sim, por condições materiais e simbólicas historicamente construídas (Brant \& Melo, 2001). Para alguns entrevistados, o processo de adoecimento aparece não como probabilidade, mas como determinante, por si só. Constatouse que o profissional, diante de uma queixa do paciente, não levava em consideração que esse processo estaria relacionado com uma multiplicidade de fatores, que era parte da própria vida e de algumas condições de trabalho. Sem essa concepção dos riscos que implicava o viver e trabalhar, o sujeito poderia ser levado a entender que a vida só seria válida quando não houvesse doença, e, quando acontece um adoecimento, se culpabiliza, o que pode resultar em uma forma de "não viver" (Castiel, 1999).

\section{Resistência}

"O clima da empresa tava pesado, procurei um médico. O médico passou antidepressivo e ansiolítico. Ele disse que era depressão. Eu não comprei o remédio. Liguei para a assistente social procurando suporte psicológico. Eu não tinha intenção de fazer uma intervenção química, mas ela indicou um psiquiatra que confirmou que era depressão e tinha que tomar remédio querendo ou não" (RT, assistente administrativo, 38 anos).

As queixas de sofrimento difuso não podem ser entendidas, a priori, como doença, manipulação ou problema de caráter, principalmente quando se trata de trabalhadores. Fruto de uma visão dicotômica do mundo e de uma formação essencialmente centrada no modelo biomédico, alguns profissionais tinham como preocupação básica a definição de um diagnóstico diferencial.
Outros centravam sua atenção na possibilidade de nexo causal entre o que se manifesta e a atividade exercida, quando se tratava de atendimento ao trabalhador. Alguns médicos pareciam desconhecer a existência do sofrimento do sujeito ou pareciam confundi-lo com doença. Esses pareciam desconhecer que, em um ambiente de trabalho onde o sofrimento não é reconhecido como tal, mas como doença, estratégias coletivas de sobrevivência são construídas. Alguns pacientes, na luta pela manutenção da vida, conseguiam articular meios para não serem identificados como doentes. Esses sabiam das conseqüências danosas do estigma de doente para a vida ocupacional, principalmente quando este envolvia a Psiquiatria. Se a internação hospitalar para o sujeito era a comprovação de estar doente, o diagnóstico psiquiátrico significava uma verdadeira condenação. Alguns pareciam compreender a visão médica do adoecimento e tentavam buscar, em outros profissionais, um lugar para o seu sofrimento. Nessa perspectiva, não cabe aqui negar a doença, mas, sim, verificar as condições de produção da identidade de doente, de maneira a analisar o uso que se faz das manifestações do sofrimento na sociedade de consumo. A relação entre esse uso, a sociedade de consumo e a atividade médica é marcadamente circular e dá-se de forma a demarcar o assentamento desses vários poderes, pois esse uso parece corresponder aos interesses dessa sociedade que, ao dividir o seu poder com a atividade médica, transfere as suas razões a essa prática (Costa, 1989).

"Não tomo os remédios, eu tomo é passe, num terreiro perto da minha casa. Falar sobre isso com os médicos, nem pensar! Com certeza, vão dizer que estou louco. Digo apenas que melhorei e eles acreditam" (WF, operário de manutenção, 28 anos).

Como forma de impedir a transformação do sofrimento em adoecimento e, em conseqüencia, a exclusão do trabalho, revelar apenas aspectos positivos da situação em que 
se encontrava e ocultar o não uso da medicação, por decisão própria ou por orientação de práticas médicas populares, constituíam algumas das estratégias dos pacientes. A renitência em fornecer informações acerca do estado de saúde acontecia, em primeiro lugar, porque o sujeito reconhecia o poder médico, e, para enfrentálo, sabia que precisava apresentar-se como doente educado, com semblante de obediente e ingênuo; segundo, porque não confiava na autoridade médica e percebia o quanto ele ignorava o seu sofrimento, reconhecendo apenas a doença. O exercício de uma medicina destituída de autoridade ocorria à medida que alguns fechavam os olhos para a transgressão no cotidiano da clínica, pois não poderíamos ser suficientemente ingênuos de acreditar que o profissional não percebia a estratégia do paciente. Médico e paciente selavam um acordo - cada um representava o seu papel social sem desvelar a realidade ao outro - e, assim, ambos iam sustentando suas posições na dinâmica da relação médico-paciente.

\section{A "escuta" diferenciada}

"Escutando tudo que eu falava, o médico percebeu que eu não estava bem. Depois, ele explicou tudinho, por que eu sentia tantas dores nas costas. Não era tão complicado" (RN, funcionária administrativa, 26 anos).

Foi possível observar, também, a existência de uma relação de confiança na consulta médica. A capacidade de escutar o paciente e reconhecer as suas condições de vida e de trabalho parece constituir-se no principal elemento para o estabelecimento de laços de confiança. A constatação de que foi ouvido se faz quando o médico lhe explica o que está sofrendo, utilizando uma linguagem imediatamente acessível, e fornece explicações que contêm representações simples do seu quadro clínico. A relação médico-paciente mediada pela escuta abre possibilidades para um processo de identificação, fazendo o paciente perceber o profissional como um sujeito, portador de uma importante função social.

\section{Considerações finais}

Tentar compreender a existência do Projeto $\mathrm{n}$ 은 25/02, relacioná-lo com a perda da autoridade médica e assinalar algumas situações que ocorrem na relação médico-paciente resultou numa produção complexa, considerando as limitações de um artigo. Ao traçarmos alguns aspectos da trajetória que vai do "nascimento de clínica" ao campo da Saúde Coletiva, no Brasil, constatamos grandes conquistas e avanços, mas também vários momentos de retrocesso, como uma relação médico-paciente às vezes permeada por situações como submissão, conflito, resistência e uma "escuta" marcada pela diferenciação. O Projeto no 25/ 02, cuja existência se deve a uma conjunção de forças culturais, corporativistas e mercadológicas, pode vir a reforçar uma dessas situações. Ao desconhecer as ações transdisciplinares que envolvem o campo da saúde e ao desconsiderar a complexidade do sujeito enquanto ser de desejo, o "ato médico", como também é conhecido esse projeto, reafirma o indivíduo como um mero portador de um corpo biológico. Ao confundir ato médico com ato do médico, esse Projeto desconheceu que a saúde ou a doença constituem diferentes pontos de vista, que a fisiologia e a patologia são uma única coisa, que não há fato patológico, e que doente e nãodoente não existem apenas como entidades biológicas (Brant, 2001).

Se a reconstrução dessa trajetória permitiu vislumbrar que, historicamente, desde o nascimento da Medicina científica, no século XIX, a Medicina tenta afirmar a sua autoridade médica em saúde diante das práticas domésticas de cuidado, as entrevistas com pacientes e médicos, embora em número reduzido, possibilitaram constatar a existência da perda dessa autoridade também na relação médicopaciente. A partir da perda da autoridade, o médico deixou ser auctor para tornar-se artifex 
no campo da saúde. A sua realização já não permanece na lembrança, tão-somente produz coeficientes de atendimento. O profissional tornou-se o representante de um universo estranho, dividido. Assim, instauraram-se dois mundos distantes, o dos médicos e o dos outros. O paciente, encarnação desse "outros", tem aguda consciência da distância social que o separa do profissional. A relação entre os médicos e os outros é uma relação de forças desiguais. Nessa desigualdade, alguns pacientes das camadas populares são tratados como consumidores, sem instrução, não estando em condições de compreender a prescrição médica, o que leva alguns profissionais a fazer indicações terapêuticas sem as devidas explicações, o que faz da relação médico-paciente uma relação de consumo. Uma sociedade de consumo, afirma Arendt (2001), "não pode absolutamente saber como cuidar do mundo e das coisas, pois a atitude de consumo condena à ruína tudo o que toca".
Criticar, discutir e recusar o Projeto no 25/02 não foi fruto de um ato simples e repentino, mas de um movimento de pesquisa e elaboração na busca de uma superação diante daquilo que o Projeto, perversamente, propõe; significou a tentativa de repensá-lo no plano epistemológico. Entendemos que esse Projeto não é obra do acaso, mas de acontecimentos; é, portanto, fruto de uma história. Concluímos, dessa forma, que os profissionais da Enfermagem, Fisioterapia, terapia ocupacional, Psicologia e Serviço Social, representantes das práticas oficiais de cuidados em saúde juntamente a todos aqueles que exercem práticas de cuidados não-oficiais, devem unirse "contra o desperdício da experiência", e, a exemplo de Santos (2000), operar uma verdadeira "crítica da razão indolente", de modo que o direito de cuidado seja uma tarefa dos homens, e não dos deuses.

\section{Marilene Barros de Melo}

Cirurgiã-dentista pela UFMG. Mestre em Saúde Coletiva pela UFMG. Especialista em Saúde Coletiva pela PUC-Minas e doutoranda em Planejamento e Gestão em Saúde pela ENSP/FIOCRUZ.

Luiz Carlos Brant

Psicólogo, Mestre em Epidemiologia pela UFMG, Especialista em dependência química pela DAY-TOP/NY-USA e Doutor em Saúde e Trabalho pela ENSP/FIOCRUZ

Av. Francisco Sales, 1614/502 - 30150-221 Belo Horizonte. E-mail:interfaz@interfaz.com.br 
ARENDT, H. O que É Autoridade? In Arendt, H. Entre o Passado e o Futuro. São Paulo: Perspectiva, 2001, pp.127-187.

BARDIN, L. Análise de Conteúdo. Lisboa: Edições 70, 1997.

BOLTANSKI, L. As Classes Sociais e o Corpo. Rio de Janeiro: Graal, 1979.

BRANT, L.C. O Indivíduo, o Sujeito e a Epidemiologia. Ciência \& Saúde Coletiva, 6(1),2001, pp.221-231.

BRANT, L.C. \& MELO, M. B. Promoção da Saúde e Trabalho: um Desafio Teórico e Metodológico para a Saúde do Trabalhador. Saúde em Debate, 25, n.57, 2001, pp.55-62 .

BRASIL/MINISTÉRIO DA SAÚDE. Relatório Final da VIII Conferência Nacional de Saúde. Brasília, MS/MPAS, (mimeo), 1986, 6p.

BRASIL/SENADO FEDERAL. Projeto de Lei no 25 (Substitutivo) de 2002. Porto Alegre: Jornal da Associação Médica do Rio Grande do Sul. Disponível em: www.coluna.com.br/noticias. Acesso em 20 nov. de 2004

BUSS, P. Promoção da Saúde e a Saúde Pública. Rio de Janeiro: ENSP/FIOCRUZ, mimeo, 1998

CANESQUI, A. M. Ciências Sociais, a Saúde e a Saúde Coletiva. In Canesqui, Ana M.(org.). Ciências Sociais e Saúde. São Paulo: Hucitec-Abrasco,1995, pp. 19- 35.

Os Novos Rumos das Ciências Sociais e Saúde. In Canesqui, A. M.(org.). Ciências Sociais e Saúde. São Paulo: Hucitec- Abrasco, 1997, pp.11-28.

CLAVREUL, J. A Ordem Médica: Poder e Impotência do Discurso Médico. São Paulo: Brasiliense, 1983.

CONSELHO FEDERAL DE MEDICINA. Resolução CFM no 1.627/ 2001. Brasília: 23/10/2001. Disponível em: http:// www.portalmedico.org.br/. Acesso em: 19 out. 2003.

CASTIEL, L. D. A Medida do Possível...Saúde, Risco e Tecnobiociências. Rio de Janeiro: FIOCRUZ, 1999.

CORRÊA, J. A. Saúde Mais. Publicação dos Conselhos Profissionais da Área da Saúde sobre o Ato Médico, 2003.

COSTA, J. F. História da Psiquiatria no Brasil. Rio de Janeiro: Xenon, 1989.

COSTA J. F. Ordem Médica e Norma Familiar. 3. ed. Rio de Janeiro: Paz e Terra, 1989.

DONNANGELO, C. A., PEREIRA, L. Saúde e Sociedade. São Paulo: Duas Cidades, 1979.

FOUCAULT, M. História da Loucura na Idade Clássica. SP: Perspectiva, 1978.

. Microfísica do Poder. Rio de Janeiro: Graal, 1979.
O Nascimento da Clínica. Rio de Janeiro: Forense, 1998.

HABERMAS, J. O Discurso Filosófico da Modernidade: Doze Lições. São Paulo: Martins Fontes, 2000.

LACAN, J. Escritos. Rio de Janeiro: Jorge Zahar, 1998.

ALONDE, M. El Concepto de "Campo de la Salud": una Perspectiva Canadiense. OPAS, Publ. Cient. 557. Washington, 1974, pp.3-5.

GIANNOTTI, J. A. Manuscritos Econômico-filosóficos e outros Textos Escolhidos/ Karl Marx. 2. ed. São Paulo: Abril Cultural. Coleção Os Pensadores, 1978.

MELO, M. B. Saúde Coletiva e Mestrado em Odontologia: um Estudo de Representação Social. Dissertação de Mestrado, Universidade Federal de Minas Gerais, Belo Horizonte, 2002.

MINAYO, M. C. S. O Desafio do Conhecimento: Pesquisa Qualitativa em Saúde. São Paulo: Hucitec-ABRASCO, 1996.

MINAYO, M. C. S. Abordagem Antropológica para Avaliação de Políticas Sociais. Revista de Saúde Pública de São Paulo, São Paulo, v.25, n.3, 1991, pp.233- 238

NUNES, E. (org.). Medicina Social: Aspectos Históricos e Teóricos. São Paulo: Global, 1983.

NUNES, E. Tendências e Perspectivas das Pesquisas em Ciências Sociais em Saúde na América Latina. In Nunes, E. D.(org.). As Ciências Sociais em Saúde na América Latina. Brasília: Organização Pan-Ameicana de Saúde, 1985, pp. 31-85.

ORTEGA Y GASSET, J. Meditação da Técnica. Rio de Janeiro: Livro Ibero-Americano, 1963.

PAIM, J. Informação e Comunicação Social em Saúde: Janelas Abertas para a Arte e para a Vida. Informação e Comunicação Social em Saúde. n. 15, 1998, pp. 55-58.

PAIM, J.: ALMEIDA-FILHO, N. Saúde Coletiva: uma "Nova Saúde Pública" ou Campo Aberto a Novos Paradigmas? Revista Saúde Pública, São Paulo, v.32, n.4, 1998, pp. 299-316.

SANTOS, B. S. A Crítica da Razão Indolente. São Paulo: Cortez, 2000 .

TRIVIÑOS, A.N.S, Pesquisa Qualitativa. In Triviños, A.N.S. Introdução à Pesquisa em Ciências Sociais: a Pesquisa Qualitativa em Educação. São Paulo: Ática, 1987, pp.116-175.

WILLIS, P. Aprendendo a Ser Trabalhador. Porto Alegre: Artes Médicas, 1991.

WITTGENSTEIN, L. Investigações Filosóficas. 2. ed. São Paulo: Abril Cultural. Coleção Os Pensadores, 1979.

WHO. Constitution of the World Health Organization. New York, 1946.

\section{Referências}

